\title{
Estimativa das taxas de desmatamento do município de Itacoatiara, Amazonas, utilizando séries Temporais Landsat-5/TM
}

Estimativas de taxas de desmatamento realizadas de forma continua utilizando técnicas de sensoriamento remoto, favorecem o monitoramento de grandes áreas como a Amazônia. Sendo assim o presente estudo objetivou estimar as taxas de desmatamento anual e diária do Município de Itacoatiara- AM, utilizando para isso imagens do satélite Landsat-5/TM. A princípio foi realizado o registro das imagens Lansat-5/TM e na sequencia calculado os valores de NDVI, o que tornou possível gerar máscaras mais fiéis aos eventos estudados. Com bases nesses valores foram calculadas taxas anuais e diárias de desmatamento para o município entre os anos de 1997 e 2011. Os resultados indicaram oscilação entre valores positivos e negativos de desmatamento para o período analisado. Foram verificadas taxas positivas de desmatamento para os anos de 2000, 2005, 2007, 2009 e 2011, com destaque para o ano de 2007 com taxa anual de desmatamento de 1438,8 km2 por ano. Ressalta-se que nos anos de 2009 e 2011 foram estimadas taxas de desmatamento relativamente baixas se comparadas com as taxas dos anos anteriores. Verificou-se que as taxas de desmatamento para o período estudado tiveram o pico em 2007 e após isso sofreram uma diminuição, isso se deve a descaracterização do município como principal como principal pólo madeireiro do estado no mesmo período. Portanto, pode-se inferir que a exploração madeireira juntamente com agropecuária são os principais agentes do desmatamento nos municípios do interior da Amazônia legal.

Palavras-chave: Supressão vegetal; NDVI; Sensoriamento Remoto.

\section{Estimates of deforestation rates in the municipality of Itacoatiara, Amazonas, through Landsat-5/TM time series}

\begin{abstract}
Continuous estimates of deforestation rates, through remote sensing techniques, increase the monitoring of large areas such as the Amazon. Therefore, the present study aimed to estimate the annual and daily deforestation rates in the municipality of Itacoatiara-AM, using images from the Landsat-5/TM satellite. At first Lansat-5/TM images were recorded and, in sequence, the NDVI values were calculated, which made it possible to generate masks more befitting the events studied. Based on these values, annual and daily deforestation rates were calculated for the municipality between 1997 and 2011. The results indicated oscillations between positive and negative deforestation values for the analyzed time series. Positive deforestation rates were verified for the years 2000, 2005, 2007, 2009 and 2011 , with emphasis on the year 2007 with an annual deforestation rate of $1438.8 \mathrm{~km} 2$ per year. It is noteworthy that in the years 2009 and 2011 , relatively low deforestation rates were estimated when compared to the rates of previous years. It was found that the deforestation rates for the period studied peaked in 2007 and after that they suffered a decrease, this is due to the lack of characterization of the municipality as the main as the main wood pole of the state in the same period. Therefore, it can be inferred that wood logging together with agriculture are the main agents of deforestation in small and medium municipalities in the interior of the legal Amazon.
\end{abstract}

Keywords: Vegetal suppression; NDVI; Remote Sensing.

Topic: Tecnologia, Modelagem e Geoprocessamento

Received: $15 / 12 / 2020$

Approved: 10/04/2021
Christiano Luna Arraes

Universidade Federal do Amazonas, Brasil http://lattes.cnpq.br/3171065144625708 christianoarraes@yahoo.com.br
Universidade Federal do Amazonas, Brasil http://lattes.cnpq.br/6779228780410672 http://orcid.org/0000-0003-1116-3051 brunomorales@ufam.edu.br

Alan Lopes da Costa

Fundação São Vicente de Paulo, Brasil http://lattes.cnpq.br/7656978472305997 lopesalan.c@gmail.com

Rodrigo Bíscaro Nogueira

Universidade Federal do Amazonas, Brasil http://lattes.cnpq.br/3518315647182183 rodrigobiscaro@gmail.com d

DOI: 10.6008/CBPC2674-6492.2021.001.0002
Referencing this:

MORALES, B. F.; COSTA, A. L.; NOGUEIRA, R. B.; ARRAES, C. L..

Estimativa das taxas de desmatamento do município de Itacoatiara, Amazonas, utilizando séries Temporais Landsat-5/TM. Environmental Scientiae, v.3, n.1, p.13-22, 2021. DOI: http://doi.org/10.6008/CBPC2674-6492.2021.001.0002 


\section{INTRODUÇÃO}

A região amazônica compreende uma área de $4.200 .000 \mathrm{~km}^{2}$ (BORELLLI, 2005), formada por distintos ecossistemas como florestas densas de terra firme, florestas estacionais, florestas de igapó, campos alagados, várzeas, savanas, refúgios montanhosos e formações pioneiras (IBF, 2017), distribuídos por nove países da América do Sul (Brasil, Bolívia, Peru, Colômbia, Equador, Venezuela, Guiana, Suriname e Guiana Francesa)

A extensão da Floresta Amazônica no Brasil, que ocupava uma área total de cerca de 3,99 milhões de quilômetros quadrados, atualmente se resume $80 \%$ da área original, com registro de perda de 780.000 $\mathrm{km}^{2}$ de vegetação nativa devido ao histórico processo de desmatamento na Amazônia Legal (INPE, 2017).

A Amazônia Legal é a parte do bioma Amazônico que se encontra dentro do território Brasileiro, formando uma região administrativa composta por nove estados (Acre, Amapá, Amazonas, Mato Grosso, Pará, Rondônia, Roraima, Tocantins, e parte do Maranhão) com aproximadamente 5,02 milhões de quilômetros quadrados abrangendo 772 municípios, o que corresponde a cerca de $60 \%$ do território brasileiro (KOHLHEPP, 2002).

O desmatamento expressivo na Amazônia Legal, segundo Tavares et al. (2012) teve início na década de 70 , devido a políticas públicas federais de expansão econômica e ocupação territorial, por meio de incentivos para que habitantes de outras regiões do território brasileiro ocupassem as terras "vazias" da Amazônia (BECKER, 2001).

Como resultado destes processos, a Amazônia Legal tem enfrentado um acelerado processo de desmatamento, sobretudo devido a atuação ilegal de madeireiras, uma vez que a supressão vegetal, quando realizada de forma intensiva e sem as devidos práticas de manejo, resulta invariavelmente em desmatamento da área (FERREIRA et al., 2015).

A exploração madeireira, realizada por empresas legalmente instituídas, devidamente autorizada pelo Órgão Ambiental competente e dotada de critérios técnicos balizados pela capacidade de suporte ecológico do ambiente configura-se como única métrica de apropriação sustentável dos recursos naturais madeireiros e manutenção dos serviços e produtos ecossistêmicos amazônicos.

Para trabalhos com delimitação espacial na região Amazônica, um dos problemas ao se trabalhar com essas técnicas segundo (LATORE et al., 2007), é a dificuldade de se obter imagens multitemporais livre de nuvens, que se configuram como um fator restritivo à discretização do conjunto de pixels que representam valores de refletância característicos para as diversas classes que pretendem ser analisadas. Neste sentido, o INPE recomenda a seleção de imagens com a menor cobertura de nuvens possível, referentes à estação seca (i.e., verão amazônico). Por outro lado, a principal vantagem está na precisão do georreferenciamento e na eficácia da classificação (CAMARA et al., 1998).

Desta forma o presente trabalho teve como objetivo estimar as taxas de desmatamento do Município de Itacoatiara-AM, utilizando séries temporais Landsat-5/TM para uma série histórica compreendida entre os anos de 1997 a 2011. 


\section{MATERIAIS E MÉTODOS}

O estudo foi realizado no Município de Itacoatiara, localizado a leste do Estado do Amazonas. Segundo Peel et al. (2007) a região enquadra se no clima equatorial húmido - $A f$, caracterizado por apresentar elevada temperatura média do ar; entre $24^{\circ} \mathrm{C}$ e $27^{\circ} \mathrm{C}$, com média mensal sempre superior a $18^{\circ} \mathrm{C}$ e alta pluviosidade, superiores a $2000 \mathrm{~mm}$ de precipitação total anual e precipitação média mensal superior a 60 $\mathrm{mm}$ para alguns meses do ano. A vegetação do município é característica do bioma amazônico.

Para a realização do trabalho foram adquiridas no site do INPE imagens orbitais do satélite Landsat5/TM, cenas com órbitas e pontos 229/62 e 230/62 (Figura 1), sendo utilizadas as bandas 3 a qual varre a região de comprimento de onda do vermelho $(0,63-0,69 \mu \mathrm{m})$ e banda 4 que varre a região do infravermelho próximo (0,76 - 0,90 $\mu \mathrm{m})$, para os anos de 1997 a 2011.

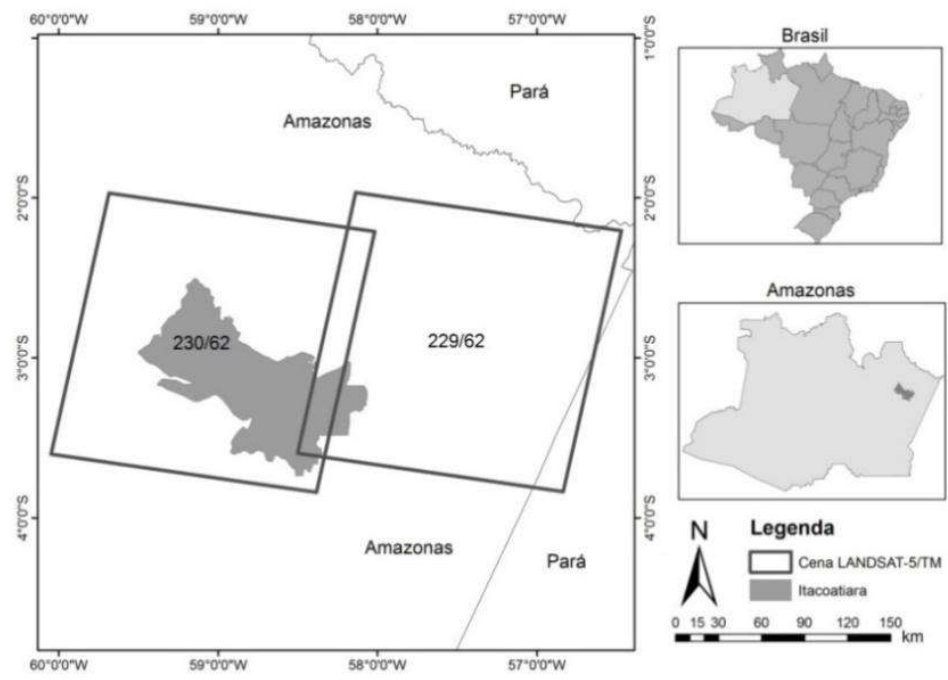

Figura 1: Tiles do satélite Landsat-5/TM que abrangem o Município de Itacoatiara-AM.

A metodologia de interpretação de imagens foi realizada em cinco etapas, sendo estas seleções de cenas, registros de imagens Landsat, cálculo dos valores de NDVI, classificação das imagens NDVI e cálculo das taxas de desmatamento.

Foram selecionadas as cenas com o mínimo possível de cobertura de nuvens, e com data de aquisição mais próxima possível da estação seca climatologicamente definida para a Amazônia, que ocorre entre o dia Juliano 151 (31 de maio) e 242 (29 de agosto) (ARRAES et al., 2010).

Os registros das imagens Landsat-5/TM foram realizados utilizando como base imagens Geocover obtendo 0,5 de erro médio quadrático (RMS) (REZENDE et al., 2013). O cálculo dos valores de NDVI seguiu a metodologia proposta por Rouse et al. (1973). Para isso foi utilizado a equação 1 proposta por Markham et al. (1987) que converte número digital (ND) em valores de radiância e na sequência em valores de refletância (em que $L_{\lambda}=$ Radiância espectral monocromática em $\mathrm{W} / \mathrm{m}^{2} . \mathrm{sr} . \mu \mathrm{m} ; N D=$ Número digital de cada pixel, no caso das imagens Landsat-5/TM podem variar de 0 a 255, pois essas imagens apresentam resolução radimétrica de 8 bits e $L_{\text {máx }}$ e $L_{\text {min }}=$ Constantes de calibração do sensor TM).

$$
L_{\lambda}=\left(\frac{L_{\text {máx }}-L_{\text {minn }}}{N D_{\text {máx }}-N D_{\text {min }}}\right) \times\left(N D-N D_{\text {mín }}\right)+L_{\text {mín }}
$$


Para o cálculo da refletância monocromática foi utilizado a equação 2 , em que $\rho_{\lambda}=$ Refletância monocromática em $\mathrm{W} / \mathrm{m}^{2}$.sr. $\mu \mathrm{m} ; d_{r}=$ inverso do quadrado da distância relativa Terra-Sol em unidades astronômicas; $E_{\lambda}=$ Irradiância solar média no topo da atmosfera em $\mathrm{m} . \mathrm{W} / \mathrm{cm}^{2} . \Omega . \mu \mathrm{m} ; L_{\lambda}=$ Radiância espectral monocromática em $\mathrm{W} / \mathrm{m}^{2}$. sr. $\mu \mathrm{m}$, já calculada pela equação 1 e $Z$ = Ângulo solar zenital em graus.

$$
\rho_{\lambda}=\left(\frac{\pi \times L_{\lambda}}{E_{\lambda} \times \cos (Z) \times d_{r}}\right)
$$

O ângulo solar zenital em graus foi calculado a partir da equação 3 , em que, $\varphi=$ Latitude do centro da imagem; $\delta=23,45^{\circ} \times \operatorname{sen}\left[\frac{360 \times(D J-80)}{360}\right] ; \omega=\left[(12-H S L) \times 15^{\circ}\right] ; H S L=$ Hora Solar Local e $D J=$ Dia Juliano.

$$
\operatorname{sen} Z=\operatorname{sen} \delta \times \operatorname{sen} \varphi+\cos \delta \times \cos \varphi \times \cos \omega
$$

Na Tabela 1 são apresentados os parâmetros utilizados para calcular os valores da refletância monocromática, como por exemplo, data de aquisição das imagens, constantes de calibração do sensor TM, inverso do quadrado da distância relativa Terra-Sol, irradiância solar média no topo da atmosfera e hora solar local.

Tabela 1: Parâmetros utilizados para calcular os valores da refletância monocromática.

\begin{tabular}{|c|c|c|c|c|}
\hline \multicolumn{5}{|c|}{ Parâmetros } \\
\hline & 01/08/1997 & $13 / 10 / 1997$ & 08/09/1999 & $15 / 07 / 1999$ \\
\hline $\operatorname{Cos}(z)$ & 0,862 & 0,485 & 0,477 & 0,43 \\
\hline $\mathrm{dr}$ & 1,015 & 0,998 & 1,007 & 1,017 \\
\hline$\alpha$ & 59,6 & 29,04 & 28,49 & 25,46 \\
\hline$\delta$ & 17,65 & $-9,22$ & 4,61 & 21,35 \\
\hline J & 213 & 286 & 251 & 196 \\
\hline
\end{tabular}
Datas

Parâmetros

\begin{tabular}{lllll} 
& $25 / 08 / 2000$ & $18 / 08 / 2000$ & $20 / 08 / 2004$ & $12 / 07 / 2004$ \\
\hline $\operatorname{Cos}(z)$ & 0,467 & 0,461 & 0,463 & 0,429 \\
$d r$ & 1,011 & 1,012 & 1,012 & 1,017 \\
$\alpha$ & 27,847 & 27,437 & 27,557 & 25,382 \\
$\delta$ & 9,59 & 12,1 & 11,4 & 21,67 \\
$\mathrm{~J}$ & 238 & 231 & 233 & 194 \\
\hline
\end{tabular}

\section{Parâmetros}

\begin{tabular}{lllll} 
& $07 / 08 / 2005$ & $01 / 09 / 2005$ & $10 / 08 / 2006$ & $03 / 08 / 2006$ \\
\hline $\operatorname{Cos}(z)$ & 0,449 & 0,475 & 0,452 & 0,446 \\
$d r$ & 1,014 & 1,009 & 1,014 & 1,015 \\
$\alpha$ & 26,7 & 28,362 & 26,885 & 26,458 \\
$\delta$ & 15,96 & 18,67 & 15,05 & 17,1 \\
$J$ & 219 & 244 & 222 & 215 \\
\hline
\end{tabular}

Parâmetros

\begin{tabular}{lllll} 
& $03 / 09 / 2007$ & $23 / 09 / 2007$ & $14 / 07 / 2008$ & $14 / 07 / 2008$ \\
\hline $\operatorname{Cos}(z)$ & 0,992 & 0,01 & 0,43 & 0,43 \\
$d r$ & 1,009 & 1,003 & 1,017 & 1,017 \\
$\alpha$ & 82,845 & 0,56 & 25,462 & 25,462 \\
$\delta$ & 6,57 & 1,41 & 21,35 & 21,35 \\
$J$ & 246 & 266 & 196 & 196 \\
\hline
\end{tabular}

Parâmetros

\begin{tabular}{lllll} 
& $02 / 08 / 2009$ & $28 / 09 / 2009$ & $08 / 08 / 2011$ & $17 / 08 / 2011$ \\
\hline $\operatorname{Cos}(z)$ & 0,445 & 0,485 & 0,45 & 0,459 \\
$d r$ & 1,015 & 1,002 & 1,014 & 1,012
\end{tabular}




\begin{tabular}{llllll}
$\alpha$ & 26,397 & 29,036 & 26,762 & 27,317 \\
$\delta$ & 17,38 & 3,41 & 15,66 & 12,78 \\
$\mathrm{~J}$ & 214 & 271 & 220 & 229 \\
\hline
\end{tabular}

$\operatorname{Cos}(z)$ - Cosseno do ângulo Zenital; dr - Distância Terra Sol; $\alpha$-Ângulo de elevação solar; $\delta$ - Declinação solar em graus; J-Dia Juliano.

Após a determinação dos valores físicos das imagens Landsat-5/TM para as bandas do vermelho e infravermelho próximo foram calculados os valores de NDVI para toda a série histórica, esses valores são contidos em uma escala que varia entre -1 e 1. Para isso utilizou-se a equação 4, proposta por Rouse et al. (1973), em que $\rho_{V}=$ Valor da refletância na faixa do vermelho em $\mathrm{W} / \mathrm{m}^{2} . \mathrm{sr}$. $\mu \mathrm{m}$ e $\rho_{I V P}=$ Valor da refletância na faixa do infravermelho próximo em $\mathrm{W} / \mathrm{m}^{2} . \mathrm{sr}$. $\mu \mathrm{m}$

$$
N D V I=\left(\frac{\rho_{I V P}-\rho_{V}}{\rho_{I V P}+\rho_{V}}\right)
$$

Para a classificação das imagens NDVI utilizando perfis temporais as imagens foram ordenadas cronologicamente o que permitiu traçar o comportamento dos valores de NDVI para o uso do solo com vegetação densa, pois quanto mais densa a vegetação maior será a refletância no comprimento de onda do infravermelho próximo, o que eleva os valores de NDVI próximos a um, permitindo assim gerar as máscaras de solo exposto e vegetação. Assim, para a obtenção das informações sobre tipo de cobertura possibilitou a obtenção das informações sobre o desmatamento na área de estudo e a avaliação da evolução deste no período analisado.

Para efetuar o cálculo da taxa anual de desmatamento (TA), de um ano para o ano subsequente, foi efetuado a diferença entre as máscaras de desmatamento calculadas para cada ano, utilizando a equação 5 (em que TA = Taxa Anual em $\mathrm{km}^{2} / \mathrm{ano}$; Def = Desmatamento em $\mathrm{km}^{2}$ e A = Ano).

$$
T A=\sum \quad \text { Def }-\sum_{A-1} \quad \text { Def }
$$

Para o cálculo da taxa diária (TD), dividiu-se a taxa anual de desmatamento (TA) pelo número de dias da estação seca equação 6 .

$$
T D=\frac{T A}{\Sigma \quad \text { Diassecos }}
$$

A quantidade de dias correspondentes à estação seca para a Amazônia é de 91 dias; começando no dia Juliano 151 (31/maio) estendendo se até o dia Juliano 242 (29/agosto).

É importante destacar que para calcular as taxas de 1999, 2004 e 2011, foi necessário adaptar a formula da taxa de desmatamento anual para a equação 7 (em que $T A=$ Taxa Anual e Def = Desmatamento).

$$
T A=\sum_{A} \quad \text { Def }-\sum_{A-n} \quad \text { Def }
$$

Essa modificação foi necessária devido a não disponibilidade de imagens para os anos de 1998, 2001, 2002, 2003 e 2010, decorrentes da grande quantidade de nuvens sobre a área de interesse.

\section{RESULTADOS E DISCUSSÃO}

A partir de imagens de satélite Landsat 5/TM, classificou-se a área territorial do município de Itacoatiara/AM quanto ao tipo de uso e ocupação do solo (Figura 2), com base nos valores de NDVI, calculados para toda série histórica. 


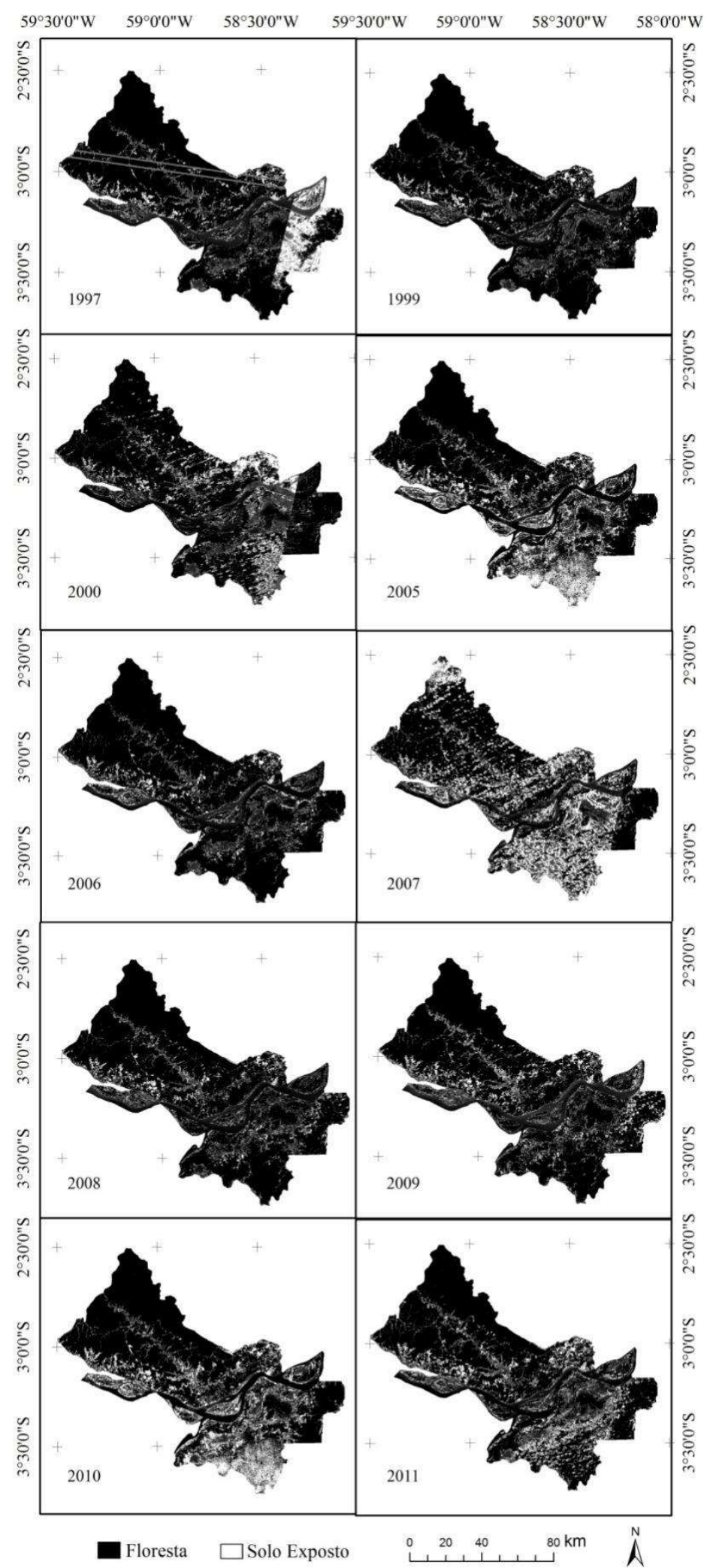

Figura 2: Evolução temporal do desmatamento no Município de Itacoatiara-AM.

Com base nos valores das taxas de desmatamento (Tabela 2), observa-se uma oscilação entre taxas negativas e positivas de desmatamento. Valores de taxa de desmatamento anual (TA) ou taxa do desmatamento diário (TD) positivas indicam aumento da área desmatada, ao tempo que valores negativos, indicam retração da taxa de desmatamento, o que leva à inferência que possivelmente houve regeneração da vegetação na área analisada (SOUZA et al., 2002). 
Tabela 2: Desmatamento, solo exposto, área não classificada e estimativa das taxas anuais e diárias do desflorestamento do Município de Itacoatiara, anos de 1997 a 2011.

\begin{tabular}{|c|c|c|c|c|c|c|c|}
\hline ANOS & $\begin{array}{l}\text { Floresta } \\
\mathrm{km}^{2}\end{array}$ & $\begin{array}{l}\text { Floresta } \\
\%\end{array}$ & $\begin{array}{l}\text { S.E. } \\
\mathrm{km}^{2}\end{array}$ & $\begin{array}{l}\text { S.E. } \\
\%\end{array}$ & $\begin{array}{l}\text { N.C. } \\
\mathrm{km}^{2}\end{array}$ & $\begin{array}{l}\text { T. A. } \\
\mathrm{km}^{2} / \mathrm{ano}\end{array}$ & $\begin{array}{l}\text { T. D. } \\
\mathrm{m}^{2} / \text { dia }\end{array}$ \\
\hline 1997 & $6.080,10$ & 68,38 & $1.102,70$ & 12,4 & $1.709,20$ & ** & $* *$ \\
\hline 1999 & $6.774,50$ & 76,19 & 657,35 & 7,39 & $1.460,10$ & $-445,4$ & $-1,63$ \\
\hline 2000 & 6.103 & 68,63 & 996,43 & 11,21 & $1.792,60$ & 339,08 & 1,24 \\
\hline 2004 & $6.576,60$ & 73,96 & 725,94 & 8,16 & $1.589,50$ & $-270,5$ & $-0,99$ \\
\hline 2005 & $6.093,90$ & 68,53 & 1102,6 & 12,4 & $1.695,50$ & 376,7 & 1,37 \\
\hline 2006 & $6.725,20$ & 75,63 & 715,93 & 8,05 & $1.450,90$ & $-386,7$ & $-1,41$ \\
\hline 2007 & $5.018,40$ & 56,44 & 2154,7 & 24,23 & $1.718,90$ & $1.438,80$ & 5,25 \\
\hline 2008 & $6.648,60$ & 74,77 & 713,05 & 8,02 & $1.530,40$ & $-1.442,00$ & $-5,26$ \\
\hline 2009 & $6.322,40$ & 71,1 & 873,65 & 9,83 & $1.696,00$ & 160,6 & 0,59 \\
\hline 2011 & $6.093,90$ & 68,53 & $1.102,60$ & 12,4 & $1.695,50$ & 229 & 0,84 \\
\hline
\end{tabular}

S.E. - Solo Exposto; N.C. - Não Classificada; T.A. - Taxa Anual; T.D.- Taxa Diária;

**falta de imagem do ano anterior a 1997.

Os valores positivos, que remetem às taxas obtidas para os anos em que realmente houve desmatamento, são visualizados para os anos de 2000, 2005, 2007, 2009 e 2011, com destaque para o ano de 2007 com Taxa anual de desmatamento de 1438,8 km² por ano. Os anos de 2009 e 2011 apresentam taxas de desmatamento relativamente baixas se comparadas com as taxas dos anos anteriores.

Portanto, após a análise das imagens classificadas, verificou se que as taxas de desmatamento para o período estudado sofreram uma diminuição, isso se deve a descaracterização do município como principal pólo madeireiro do estado, em Itacoatiara atuam três grandes segmentos da indústria madeireira, que são: a indústria de serraria, laminados e compensados e de produção de móveis. Porém nos últimos anos as atividades madeireiras vem perdendo força, segundo Campos (2013) o declínio do setor madeireiro no município teve início na década de 90, com o fechamento de quatro das cinco madeireiras de grande porte que atuavam no município, já a indústria de móveis hoje trabalha apenas sob encomenda. Esse enfraquecimento no setor madeireiro é apontado como possível fator da diminuição das taxas de desmatamento do Município de Itacoatiara.

No entanto, a regeneração integral da área desmatada, conforme verificado por (CHAZDON, 2012), com recomposição florestal, não é possível em um curto intervalo de tempo. Isto ocorre devido a sequência obrigatória de substituição/alternância de espécies em um processo de natural de sucessão ecológica, durante a colonização de áreas com solos expostos. As espécies vegetais de maior porte apresentam elevadas necessidades ecológicas (nutricionais, edáficas, interacionais, dentre outras) que tornam inviável sua imediata ocorrência em solo expostos, devido às condições ambientais adversas geradas pelo desmatamento (LIKENS et al., 2013), como aumento da taxa de insolação, efeitos da ação direta dos ventos, herbivoria e competição.

Como o NDVI está relacionado com a condição presença/ausência de vegetação, a ocorrência de valores negativos para os anos de 1999, 2004, 2006 e 2008, com alternância entre anos com valores positivos de desmatamento, podem estar possivelmente relacionados a presença de cobertura dos solos anteriormente desmatados por espécies vegetais que não tem a capacidade suporte populacional, como um fator restritivo.

Tais espécies, conforme o modelo populacional proposto por Verhulst (1837, citado por ODUM, 
1990) são consideradas " $r$ " estrategistas (i.e., gramíneas, lianas, etc.), por suas populações serem formadas por indivíduos que apresentam tempo de vida mais curto e tendência a explorar nichos ecológicos vazios. Também geram elevado número de descendentes por ciclo reprodutivo, podendo apresentar picos populacionais, ocupando rapidamente áreas integralmente expostas, como é o caso de áreas de desmatamento raso (remoção total da cobertura florestal).

Em situações de desmatamento seletivo, que consiste na supressão vegetal direcionada exclusivamente a recursos florestais madeireiros, a Resolução CONAMA Na 406 de 02 de fevereiro 2009 (CONAMA, 2009) define o Diâmetro Mínimo de Corte (DMC) de $50 \mathrm{~cm}$ para todas as espécies, à exceção das que possuem o DMC específico.

A referida resolução estabelece parâmetros técnicos a serem adotados na elaboração, apresentação, avaliação técnica e execução de Plano de Manejo Florestal Sustentável-PMFS com fins madeireiros, para florestas nativas e suas formas de sucessão no bioma Amazônia. Nesse sentido, as ações de supressão vegetal com fins madeireiros devidamente autorizados pelo Órgão Ambiental Competente, que no caso do Estado do Amazonas é o Instituto de Proteção Ambiental do Estado do Amazonas (IPAAM), propiciarão a retirada de espécies vegetais de grande porte em quantidades suficiente para formas clareiras em áreas florestais.

A abertura de clareiras possibilita maior insolação devido a diminuição do sombreamento provocado por espécies vegetais de grande porte, o que pode possibilitar, além do incremento de populações de espécies "r" estrategistas, a reativação do banco de sementes pela quebra de dormência e germinação de sementes de espécies vegetais heliófitas, que proporcionarão a composição de um extrato vegetal de cobertura do terreno que podem justificar os valores negativos de NVDI.

O problema do desmatamento na Amazônia é bastante complexo e por isso não pode ser atribuído a um único agente, na realidade, ele é a soma de um conjunto de agentes e fatores que como consequência resulta neste fenômeno. Porém, é inegável que a exploração madeireira juntamente com agropecuária são os principais agentes do desmatamento nos municípios da Amazônia legal.

Assim, ressalta-se a necessidade de consolidação das políticas públicas voltadas à preservação ambiental, a criação de unidades de conservação e o aumento dos investimentos em fiscalização e fortalecimento das instituições de controle, monitoramento e fiscalização ambiental tornaram-se efetivas no combate ao desmatamento na Amazônia Legal, reduzindo de forma expressiva suas taxas.

A atuação integrada e complementar de programas, órgãos e instituições públicas e instituições e organizações privadas, organizações da sociedade civil de interesse público (OSCIPs), organizações nãogovernamentais (ONGs), institutos de pesquisa e movimentos sociais, aumentaram o potencial de maior eficácia de ações de controle ao desmatamento. Dentre estes destacam-se o Instituto Chico Mendes de Conservação da Biodiversidade (ICMBio), Instituto Brasileiro do Meio Ambiente e dos Recursos Naturais Renováveis (IBAMA), Instituto de Proteção Ambiental do Estado do Amazonas (IPAAM), Polícia Federal, Sistema de Monitoramento do Desmatamento na Amazônia Legal (PRODES/INPE), Sistema deteç̧ão do desmatamento em tempo real (DETER/INPE), (IMAZON), Instituto Nacional de Pesquisas da Amazônia (INPA). 


\section{CONCLUSÕES}

As imagens NDVI, em comparação com as imagens "brutas", apresentaram maior potencial na classificação das áreas, solo exposto e vegetação, por não classificar grande quantidade de nuvens. Dessa forma, a metodologia desenvolvida pelo INPE para o cálculo da taxa diária e anual do desmatamento mostrou ser uma ferramenta eficiente e de uso simples, características que foram fundamentais para obtenção das taxas de desmatamento.

O desmatamento ocorrido no ano de 2007 foi o maior da série histórica, seguidos pelos anos de 2005, 2000, 2011 e 2009. O problema do desmatamento na Amazônia é bastante complexo e por isso não pode ser atribuído a um único agente, na realidade, ele é a soma de um conjunto de agentes e fatores que como consequência resulta neste fenômeno. Porém, é inegável que a exploração madeireira juntamente com agropecuária são os principais agentes do desmatamento nos municípios da Amazônia legal.

Ações voltadas para o monitoramento e fiscalização do desmatamento, aliadas às políticas públicas e utilização de ferramentas espaciais que possibilitam maior acurácia na obtenção de informações para regulação em tempo real da condição ambiental de áreas florestais são essenciais para a perduração espacial e temporal das florestas e consequentemente do bioma amazônico.

\section{REFERÊNCIAS}

ARRAES, C. L.; ROCHA, A. M.; MORAES, R. A.; PISSARRA, T. C. T.; RODRIGUES, F. M.; ZANATA, M.. Estimativa da taxa de desmatamento de desmatamento do município de Bannach, Para Amazônia Legal, utilizando imagens landsat T5/TM. Revista de Ciências Agrárias, Lisboa, v.5, n.3, p.231-243, 2010.

BECKER, K. B.. Revisão das políticas de ocupação da Amazônia: é possível identificar modelos para projetar cenários?. Parcerias Estratégicas, v.6, n.12, p.135-159, 2001

BORELLLI, D. L.. Aziz Ab'Sáber: problemas da Amazônia brasileira. Estudos Avançados, São Paulo, v.19, n.53, p.7-35, 2005. DOI: http://doi.org/10.1590/S010340142005000100002

CAMARA, G.; MEDEIROS, J. S.. Princípios Básicos em Geoprocessamento. In: ASSAD, E. D.; SANO, E. E.. Sistema de informações geográficas: aplicações na agricultura. Brasília: EMBRAPA, 1998. p.3-11.

CAMPOS, F. D.. Percepções ambientais sobre a madeira: usos e significados no polo madeireiro de Itacoatiara-AM. Dissertação (Mestrado em Ciências do Ambiente e Sustentabilidade na Amazônia) - Universidade Federal do Amazonas, Manaus, 2013.

CHAZDON, R.. Regeneração de florestas tropicais. Boletim do Museu Paraense Emílio Goeldi Ciências Naturais, Belém v.7, n.3, p.195-218, 2012.

CONAMA. Conselho Nacional de Meio Ambiente. Resolução CONAMA Na 406 de 02 de fevereiro de 2009. Estabelece parâmetros técnicos a serem adotados na elaboração, apresentação, avaliação técnica e execução de Plano de Manejo Florestal Sustentável-PMFS com fins madeireiros, para florestas nativas e suas formas de sucessão no bioma Amazônia. Brasília: CONAMA, 2009.

FERREIRA, B. M.; RIBEIRO, E. G. P.; PEREIRA, B. W. F.; PINHEIRO, P. F. V.; MACIEL, M. N. M.. Imagens Orbitais na Análise da Degradação Florestal e Qualidade do Manejo em Área de Exploração no Município de Paragominas-PA. Enciclopédia Biosfera, Goiânia, v.11, n.21, p.3151-3165, 2015.

IBF. Instituto Brasileiro de Florestas. Bioma Amazônico. IBF 2017.

INPE. Instituto Nacional de Pesquisas Espaciais. INPE registra 6.947 km2 de desmatamento na Amazônia em 2017. São José dos Campos: INPE, 2017.

KOHLHEPP, G.. Conflitos de interesse no ordenamento territorial da Amazônia brasileira. Estudos Avançados, v.16, n.45, p.37-61, 2002. Dol: http://doi.org/10.1590/S010340142002000200004

LATORE, M. I.; CARVALHO, A. O.; SANTOS, J. R.; SHIMABUKURO, Y. E.. Integração de Dados de Sensoriamento Remoto Multi Resoluções Para a Representação da Cobertura da Terra Utilizando Campos Contínuos de Vegetação e Classificação por Árvores de Decisão. Revista Brasileira de Geofísica, v.1, n.25, p.63-74, 2007. DOI: http://doi.org/10.1590/S0102261X2007000100006

LIKENS, G. E.; STRAYER, D.; WEATHERS, K. C.. Fundamentos de ciência dos ecossistemas. São Paulo: Elsevier, 2013.

MARKHAM, B. L.; BARKER, J. L.. Radiometric Properties of U.S. processes Landsat MSS data. Remote Sensing of 
Environment, v.22, n.1, p.39-71, 1987. DOI: http://doi.org/10.1016/0034-4257(87)90027-7

ODUM, E. P.. Ecologia. Rio de Janeiro: Guanabara S.A., 1990.

PEEL, M. C.; FINLAYSON, B. L.; MCMAHON, T. A.. Updated world map of the Köppen-Geiger climate classification. Hydrological Earth System Science, v.4, n.2, p.1633-1644, 2007. DOI: http://doi.org/10.5194/hess-11-1633-2007

REZENDE, G.; ALVES, L. B. T.; VASCONCELOS, D. C.;

PINHEIRO, P. B.. Identificação do desmatamento através da análise comparativa do Normalize Difference Vegetation Index (NDVI) e Ratio Vegetation Index (RVI). In: SIMPÓSIO BRASILEIRO DE SENSORIAMENTO REMOTO - SBSR, 16.

Anais. Foz do Iguaçu: INPE, 2013. p.4411-4418.
ROUSE, J. W.; HAAS, R. H.; SCHELL, J. A.; DEERING, D. W. Monitoring vegetation systems in thegreat plains with ERTS. In: EARTH RESOURCES TECHNOLOGY SATELLITE- 1 SYMPOSIUM, 3. Anais. Washington: NASA, Goddart Space Flight Center, 1973. p.309- 317.

SOUZA, A. L.; SCHETTINO, S.; JESUS, R. M.; VALE, A. B. Dinâmica da regeneração natural em uma floresta ombrífila densa secundaria, após corte de cipós, reserva natural da companhia Vale do Rio Doce S.A, Estado do Espírito Santo, Brasil. Revista Árvore, v.26, n.4, p.411-419, 2002. DOI: http://doi.org/10.1590/S0100-67622002000400003

TAVARES, A.; PEREIRA, J.. Análise do Desflorestamento ao Longo da Rodovia Cuiabá-Santarém (BR-163). In: ENCONTRO NACIONAL DAS ANPPAS, 6. Anais. Belém: NAEA-UFPA, 2012. p.3.

A CBPC - Companhia Brasileira de Produção Científica (CNPJ: 11.221.422/0001-03) detém os direitos materiais desta publicação. Os direitos referem-se à publicação do trabalho em qualquer parte do mundo, incluindo os direitos às renovações, expansões e disseminações da contribuição, bem como outros direitos subsidiários. Todos os trabalhos publicados eletronicamente poderão posteriormente ser publicados em coletâneas impressas sob coordenação da Cognitionis Publishing, da Companhia Brasileira de Produção Científica e seus parceiros autorizados. Os (as) autores (as) preservam os direitos autorais, mas não têm permissão para a publicação da contribuição em outro meio, impresso ou digital, em português ou em tradução. 